\section{Elizabeth I}

Sir: I was fascinated to read Dr Knapp's account of the portrait of Elizabeth I (Psychiatric Bulletin. 19. May 1995, 307-308). I agree with her about its artistic qualities and admire the skdll at which Dr Knapp has brought out the symbolic importance of the picture's various features. However, I am less certain about her interpretation of the picture's psychological message, as accurately recording the psychological status of a child from an abustve and neglected childhood.

The time the picture was made, Elizabeth was clearly of marriageable age. Heads of State unions were arranged marriages, and frequently pictures of the proposed bride were sent with the initial proposals as a way of giving the other side an impression of who it was they were to marry. Of course, the people such portraits were to please were not the intended spouse, but the spouse's parents. Furthermore, at this level, qualities looked for in a wife were (aside from baby making), sobriety, religious devotion and fidelity. One can understand many of the rather sombre characteristics of Elizabeth's portrait in these terms. An additional example of such symbolism can be seen in her dress, with its stylised pattern of unfolding flower buds suggesting both virginity and fecundity. Of course, these pictures were frequently adjusted to ensure that the recipients saw what they wanted to see, and you may recall that Henry VIII was indeed tricked by just such a picture in his agreement to marry Catherine of Aragon. When assessing paintings from a particular era, it is dangerous to make interpretations that do not take into account the context in which they were painted.

D. M. FOREMAN

Abbey Hulton Service, Leek Road, Abbey Hulton, Stoke on Trent, Staffs ST2 8BP

Sir: Dr Foreman's suggestion as to the purpose for which the portrait was commissioned is convincing, and his contribution enhanced my enjoyment of the picture, but I don't think it detracts from my central point. Elizabeth would never have seen herself as a victim and nor would the artist, for whatever reason it was painted. A good artist will portray more than he sees and we who come after will find insights into the sitter of which neither are consciously aware.

\section{ELINOR KAPP}

Gwent Community Health, National Health

Service Trust, St Cadoc's Hospital,

Gwent NP6 1XQ 